\title{
CrystEngComm
}

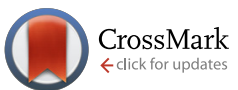

Cite this: CrystEngComm, 2015, 17, 1693

Received 24th November 2014, Accepted 2nd January 2015

DOI: $10.1039 / c 4 c e 02324 b$

www.rsc.org/crystengcomm

\section{Metal organic framework synthesis in the presence of surfactants: towards hierarchical MOFs? $\dagger$}

\author{
B. Seoane, ${ }^{\star a}$ A. Dikhtiarenko, ${ }^{a}$ A. Mayoral, ${ }^{\text {bc }}$ C. Tellez, ${ }^{b}$ J. Coronas, ${ }^{b}$ F. Kapteijn ${ }^{a}$ \\ and J. Gascon*a
}

\begin{abstract}
The effect of synthesis $\mathrm{pH}$ and $\mathrm{H}_{2} \mathrm{O} / \mathrm{EtOH}$ molar ratio on the textural properties of different aluminium trimesate metal organic frameworks (MOFs) prepared in the presence of the well-known cationic surfactant cetyltrimethylammonium bromide (CTAB) at $120^{\circ} \mathrm{C}$ was studied with the purpose of obtaining a MOF with hierarchical pore structure. Depending on the $\mathrm{pH}$ and the solvent used, different topologies were obtained (namely, MIL-96, MIL-100 and MIL-110). On the one hand, MIL-110 was obtained at lower temperatures than those commonly reported in the literature and without additives to control the $\mathrm{pH}$; on the other hand, MIL-100 with crystallite sizes as small as $30 \pm 10 \mathrm{~nm}$ could be easily synthesized in a mixture of $\mathrm{H}_{2} \mathrm{O}$ and $\mathrm{EtOH}$ with a $\mathrm{H}_{2} \mathrm{O} / \mathrm{EtOH}$ molar ratio of 3.4 at $\mathrm{pH} 2.6$ in the presence of CTAB. The resulting material displays a hierarchical porosity that combines the microporosity from the MOF and the nonordered mesopores defined in between the MOF nanoparticles. Interestingly, the maximum of the pore size distribution could be varied between 3 and $33 \mathrm{~nm}$. Finally, at pH 2.5 and using water as a solvent, platelets of MIL-96, a morphology never observed before for this MOF, were synthesized with a (001) preferential crystal orientation, the (001) plane running parallel to the bipyramidal cages of the MIL-96 topology.
\end{abstract}

\section{A Introduction}

Metal-organic frameworks (MOFs) are ordered porous crystalline materials resulting from the self-assembly of metal ions or clusters with organic linkers possessing carboxylates, phosphonates, sulfonates or N-containing multidentate ligands. ${ }^{1}$ Due to their outstanding textural properties, ${ }^{2}$ flexibility ${ }^{3}$ and rich pre- $-{ }^{4,5}$ and post- ${ }^{6}$ synthesis chemistry, MOFs are very versatile architectures with promising applications in the fields of adsorption, ${ }^{2}$ encapsulation, ${ }^{7}$ drug delivery, ${ }^{8}$ catalysis, ${ }^{9}$ membranes ${ }^{10,11}$ and separation and storage of gases and vapors, ${ }^{11}$ among others. However, while high micropore volumes and large surface areas are desirable for many applications, such narrow pores do not allow inclusion or anchoring of bulky host molecules. Moreover, diffusive transport in micropores may limit catalytic and separation performance; $^{12}$ therefore, the synthesis of MOFs with a

\footnotetext{
${ }^{a}$ Catalysis Engineering, ChemE, Delft University of Technology, Julianalaan 136, 2628 BL Delft, The Netherlands. E-mail: B.SeoanedelaCuesta@tudelft.nl, j.gascon@tudelft.nl; Fax: +31 1527 85006; Tel: +31 152784851

${ }^{b}$ Chemical and Environmental Engineering Department and Nanoscience Institute of Aragon (INA), Universidad de Zaragoza, Mariano Esquillor, Edificio I+D, 50018, Zaragoza, Spain

${ }^{c}$ Advanced Microscopy Laboratory (LMA), Nanoscience Institute of Aragon (INA), Universidad de Zaragoza, Mariano Esquillor, Edificio I+D, 50018, Zaragoza, Spain $\dagger$ Electronic supplementary information (ESI) available. See DOI: 10.1039/ c4ce02324b
}

hierarchical pore structure, combining pores below and over $2 \mathrm{~nm}$, would offer several advantages.

In this spirit, different approaches have been reported to manufacture mesoporous MOFs $\left(2 \mathrm{~nm}<d_{\mathrm{p}}<50 \mathrm{~nm}\right){ }^{13-15}$ As template free synthesis strategies, ligand extension, microemulsion methods and nanocrystal self-assembly have been reported. Furthermore, different surfactants have been used to obtain mesoporous MOFs where a long-range order has been claimed.

Ligand extension, or more precisely SBU extension, is an attractive strategy leading to the synthesis of different MOFs with mesoporous channels such as IRMOF-16 ${ }^{4}$ and MesoMOF- $1^{16}$ or cavities like MIL-100, ${ }^{17}$ MIL-101, ${ }^{18,19}$ ZIF-95, ZIF-100 ${ }^{20}$ and NU-100 (also termed PCN-610). ${ }^{21}$ However, introducing longer bridging ligands presents difficulties. ${ }^{22}$ On the one hand, the product obtained often exhibits framework interpenetration to maximize the packing efficiency; ${ }^{23}$ on the other hand, the structure may collapse upon guest removal. Together with SBU extension, other surfactant-free approaches such as microemulsions and nanocrystal assembly have also been applied to obtain MOFs with mesopores. As an example of the latter, Yue $e t a l .^{24}$ reported the synthesis of Zn-MOF-74 with disordered mesopores with widths of 5-20 nm formed between the nanosized MOF crystals.

The use of surfactants as structure directing agents has been extensively applied to the supramolecular templatedirected synthesis of different materials such as mesoporous 
silicas, aluminosilicates and other mesostructured metal oxides. Thus, it also seems to be an attractive strategy to obtain mesoporosity in MOFs. ${ }^{25}$ Since the pioneering work of Roy et al., ${ }^{26,27}$ in which the synthesis of the first liquidcrystal templated mesoporous MOF was accomplished with self-made surfactants that bind alkyl chains to the organic ligands of different Prussian blue analogues, several examples of surfactant templated MOFs have been published. Qui et $a{ }^{28}{ }^{28}$ reported the synthesis of HKUST-1 in the presence of the cationic surfactant cetyltrimethylammonium bromide (CTAB) and the organic compound 1,3,5-trimethylbenzene (TMB) as a micelle swelling agent. In contrast to other mesoporous materials such as silicas that exhibit amorphous walls, Qui et al. obtained a hierarchical MOF in which the walls of the mesopores were composed of crystalline microporous HKUST-1. ${ }^{28}$ Zhao et al. ${ }^{29}$ synthesized nanospheres with long-range ordered mesopores in an emulsion system containing an ionic liquid, supercritical $\mathrm{CO}_{2}$ and the surfactant $\mathrm{IL} / \mathrm{SCCO}_{2} / \mathrm{N}-\mathrm{EtFOSA}$ and $\mathrm{Ma}$ et $a .^{30}$ reported the synthesis of crystalline metal disulfonates with wellstructured hexagonal mesoporosity controlling the release of the metal ions by a crown ether and using F-127 as a nonionic surfactant.

One of the most studied subclasses of MOFs is the MIL (MIL stands for Material Institute Lavoisier) family in which the metal node is commonly a trivalent cation and the ligand a di-, tri- or tetracarboxylic acid. Employing 1,3,5-benzenetricarboxylic acid (trimesic acid) as a linker and aluminium as the metal node, three different topologies have been reported: MIL-96, ${ }^{31}$ MIL-100 ${ }^{32}$ and MIL-110. ${ }^{33}$ In all these structures the aluminium atoms are octahedrally coordinated. However, while MIL-110 exhibits inorganic octameric motifs connected by trimesate molecules to form hexagonal $16 \AA$ channels, ${ }^{33}$ MIL-96 and MIL-100 contain trimeric units. MIL-100 displays the MTN zeolitic topology with mesoporous cavities of 25 and $29 \AA$ and microporous pentagonal and hexagonal windows of $4.8 \times 5.8 \AA$ and $8.6 \times$ $8.6 \AA$ A respectively. ${ }^{32}$ MIL-96 contains isolated trinuclear clusters of $\mu_{3}$-O bridged metallic octahedra together with infinite corrugated chains of $\mathrm{AlO}_{4}(\mathrm{OH})_{2}$ and $\mathrm{AlO}_{2}(\mathrm{OH})_{3}\left(\mathrm{H}_{2} \mathrm{O}\right)$, generating a hexagonal network with three types of cavities, two of them having a trigonal bipyramidal shape and a free diameter of $8.8 \AA^{31}$

In this manuscript we present a thorough study on the effect of different synthesis conditions on the textural properties of different aluminium trimesate MOFs when synthesized in the presence of CTAB. This strategy enabled the synthesis of MOFs with hierarchical porosity combining both the micropores of the MOF topology and the mesopores created by the aggregation of the MOF nanoparticles.

\section{B Experimental}

\section{Synthesis}

In a typical synthesis, $0.844 \mathrm{~g}$ of $\mathrm{Al}\left(\mathrm{NO}_{3}\right)_{3} \cdot 9 \mathrm{H}_{2} \mathrm{O}(\geq 98 \%$, Sigma-Aldrich) was dissolved in $15 \mathrm{~mL}$ of distilled water, and
$0.331 \mathrm{~g}$ of trimesic acid $\left(\mathrm{H}_{3} \mathrm{BTC}, \geq 97 \%\right.$, Sigma-Aldrich $)$ and $1.004 \mathrm{~g}$ of cetyltrimethylammonium bromide (CTAB, $\geq 98 \%$, Sigma-Aldrich) were dissolved separately in $15 \mathrm{~mL}$ of EtOH ( $\geq 99 \%$, Sigma-Aldrich). Subsequently, the aqueous solution was poured into the ethanolic solution and stirred for $30 \mathrm{~min}$ at RT. The final $\mathrm{CTAB} / \mathrm{Al}$ and $\mathrm{H}_{2} \mathrm{O} / \mathrm{EtOH}$ molar ratios were 0.6 and 3.4, respectively, and the $\mathrm{pH}$ of the synthesis solution was 2.1. The mixture was transferred to a Teflon ${ }^{\circledR}$-lined stainless steel autoclave and heated at $120{ }^{\circ} \mathrm{C}$ for $12 \mathrm{~h}$ under static conditions. After cooling down, the product was filtered off and washed with fresh EtOH. Finally, to activate the MOFs, $100 \mathrm{mg}$ were suspended in $100 \mathrm{~mL}$ of EtOH and kept under reflux at $60{ }^{\circ} \mathrm{C}$ overnight, filtered off and dried overnight at room temperature.

To study the influence of different synthesis parameters on the final product, several synthesis conditions were tested. The $\mathrm{pH}$ was modified between 2.1 and 2.7 by adding different amounts of tetramethylammonium hydroxide (TMAOH, 25 wt.\%, Sigma-Aldrich); the $\mathrm{H}_{2} \mathrm{O} / \mathrm{EtOH}$ ratio was changed in the range 1.5 to $\infty$ and four different values for the $\mathrm{CTAB} / \mathrm{Al}$ molar ratio $(0,0.3,0.6$ and 1.2$)$ were employed (see Table $\mathrm{S} 1 \dagger)$. Depending on the synthesis conditions, three different phases, MIL-96, MIL-100, and MIL-110, or mixtures of them were obtained.

\section{Characterization}

Data from $\mathrm{N}_{2}$ adsorption were collected at $77 \mathrm{~K}$ on a Quantachrome Autosorb-6B setup. Prior to the measurements the powder samples were outgassed overnight at $130{ }^{\circ} \mathrm{C}$ (heating rate: $1^{\circ} \mathrm{C} \mathrm{min}^{-1}$ ). BET surface areas were determined from the adsorption branches according to the criteria reported by Walton et al., Rouquerol et al. and de Lange et $a .^{34-36}$ The external specific surface area and the micropore volume were both calculated by means of the $t$-plot method and the micropore specific surface area was calculated by subtracting $S_{\mathrm{EXT}}$ from $S_{\mathrm{BET}}$. Finally, pore size distributions were calculated using the Barrett-Joyner-Halenda (BJH) model using the adsorption branches to avoid the influence of $\mathrm{N}_{2}$ cavitation (vide infra).

$\mathrm{XRD}$ was performed at room temperature using a BrukerAXS D5005 with CoK $\alpha$ radiation $(\lambda=1.7890 \AA)$. All data were collected at room temperature over the angular $2 \theta$ range $5-40^{\circ}$ with a step of $0.011^{\circ}$. In order to confirm the preferred orientation of the laminar MIL-96(Al) crystals, pattern matching (profile refinement) was performed in the range 5-40 ${ }^{\circ}$ using FullProf software. ${ }^{37}$ A Pearson VII function was chosen to generate the line shape of the diffraction peaks. Zero offset, the scale factor, six background terms, profile parameters, preferred orientation obtained using the MarchDollase function and unit cell parameters were refined.

SEM images were acquired with an Inspect $\mathrm{F}$ scanning electron microscope (FEI) operating at $10 \mathrm{kV}$.

Prior to the STEM analyses, the samples were dispersed in EtOH. After sonication a few drops of the suspension were placed onto a holey carbon copper microgrid. STEM analysis 
was performed using an aberration $\left(C_{\mathrm{s}}\right)$ corrected FEI Titan operated at $300 \mathrm{kV}$, equipped with a Gatan bottom-entry CCD $2 \mathrm{~K} \times 2 \mathrm{~K}$ digital camera, an EDS detector for chemical analysis, a STEM (BF/ADF/HAADF detector) module and a CEOS corrector for the electron probe.

Infrared spectra were recorded on a Bruker model IFS66 spectrometer in DRIFT mode in a high temperature cell with $\mathrm{CaF}_{2}$ windows. The spectra were collected after accumulation of 128 scans with a resolution of $4 \mathrm{~cm}^{-1}$. Before collecting the spectra, the sample was pretreated in the equipment under helium at $393 \mathrm{~K}$ for $1 \mathrm{~h}$.

Thermogravimetric analysis was performed in a system provided by Mettler Toledo, model TGA/SDTA851e under air flow of $60 \mathrm{~mL} \mathrm{~min}{ }^{-1}$ at a heating rate of $10{ }^{\circ} \mathrm{C} \min ^{-1}$ up to $850{ }^{\circ} \mathrm{C}$.

\section{Results and discussion}

Fig. 1 shows the XRD pattern of the sample synthesized from a synthesis solution of $\mathrm{pH} 2.1$ with CTAB/Al and $\mathrm{H}_{2} \mathrm{O} / \mathrm{EtOH}$ molar ratios of 0.6 and 3.4, respectively. The reflections observed match with those of the MIL-110 topology ${ }^{17}$ together with some impurities, the latter giving rise to a broad signal at $2 \theta \approx 12.4^{\circ}$. The presence of impurities in the synthesis of MIL-110 was already reported by Haouas et al. ${ }^{38}$ In fact, similar SEM images were obtained with two different morphologies: needle-like crystals characteristic of MIL-110 and spherical amorphous particles corresponding to the impurities observed by XRD (see Fig. S1†).

In the literature, different methods have been published in order to obtain MIL-110..$^{33,39-41}$ Typically, the synthesis has been carried out in water at $210{ }^{\circ} \mathrm{C}$ by controlling the $\mathrm{pH}$ using either mineral acid, $\mathrm{HNO}_{3}$, or mineral base, $\mathrm{NaOH}$, as a pH adjustment additive. ${ }^{33,39}$ Most of the syntheses reported to date have been performed at $\mathrm{pH} \approx 0$ or $\mathrm{pH} \approx 4$, although synthesis at $\mathrm{pH} 7$ has been successful as well. ${ }^{39,40}$ While the most common solvent to obtain MIL-110 is distilled water, the MIL-110 topology has also been observed as an impurity

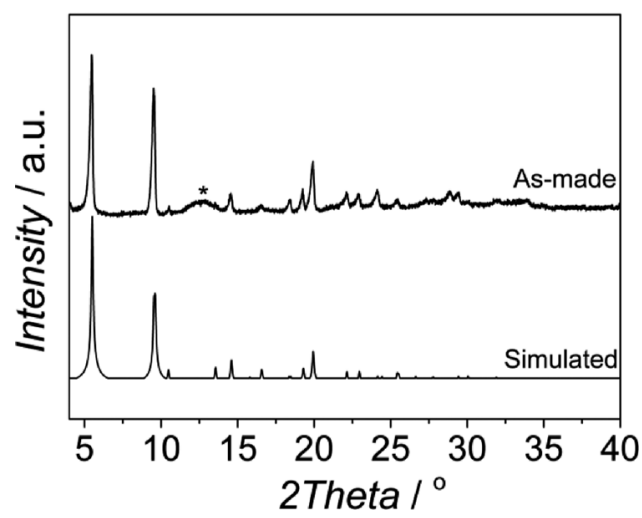

Fig. 1 XRD pattern of the sample obtained at $120{ }^{\circ} \mathrm{C}$ from a synthesis solution with $\mathrm{pH} 2.1$ and $\mathrm{CTAB} / \mathrm{Al}$ and $\mathrm{H}_{2} \mathrm{O} / \mathrm{EtOH}$ molar ratios of 0.6 and 3.4, respectively, together with the MIL-110 simulated pattern from the data previously reported by Volkringer et al. ${ }^{33}$ when a mixture of $\mathrm{DMF} / \mathrm{H}_{2} \mathrm{O}$ was used. ${ }^{41}$ Besides, the synthesis of MIL-110 aerogels in EtOH at $80{ }^{\circ} \mathrm{C}$ has been recently reported. Although the authors claimed that the XRD pattern could not be assigned to a known single MOF phase, the isolated aerogel is, according to the published XRD pattern, related to the MIL-110 network. ${ }^{42}$ In this work, MIL-110 could be obtained using a mixture of water and ethanol at lower temperatures and without additives to control the $\mathrm{pH}$. Furthermore, the BET surface area, calculated from the $\mathrm{N}_{2}$ isotherm acquired at $77 \mathrm{~K}$, was $1360 \mathrm{~m}^{2} \mathrm{~g}^{-1}$ which is very close to the value previously reported. ${ }^{33}$ However, even though the synthesis was carried out with a $\mathrm{CTAB} / \mathrm{Al}$ ratio of 0.6 , the isotherm showed a type I behavior and no hysteresis was observed, giving no evidence of any mesoporosity in the sample (see Fig. S2†).

\section{Influence of $\mathrm{pH}$}

The $\mathrm{pH}$ was reported to be a parameter with great influence on the synthesis of Al based MOFs with trimesic acid as an organic ligand. ${ }^{38,43}$ Based on these reports, we varied the $\mathrm{pH}$ between 2.1 and 2.7. When no base was used ( $\mathrm{pH} 2.1$ ), MIL-110 was formed together with some impurities (Fig. 1).

At higher $\mathrm{pH}$ values MIL-100 started to form (see Fig. 2 and Fig. S3†), being the main product in the $\mathrm{pH}$ range 2.3-2.5, and at $\mathrm{pH} 2.6$ the sample produced was a mixture of MIL-100 and MIL-96, the relative amount of the latter becoming more important when the $\mathrm{pH}$ was further increased. This behavior is different from that previously reported. In water, MIL-110 was isolated at very acidic $\mathrm{pH}$ $(\mathrm{pH} \approx 0-0.3)$, MIL-100 was also synthesized in a very narrow $\mathrm{pH}$ range $(0.5<\mathrm{pH}<0.7)$, MIL-96 was obtained at $\mathrm{pH} 1-3$ and MIL-110 appeared again at $\mathrm{pH} 4 .^{31,32,39}$ Even though the trend could be the same, the $\mathrm{pH}$ ranges at which the different topologies were observed are very different under the conditions studied.

The $\mathrm{N}_{2}$ adsorption results and SEM images were in agreement with the XRD patterns obtained. At $\mathrm{pH}$ values of

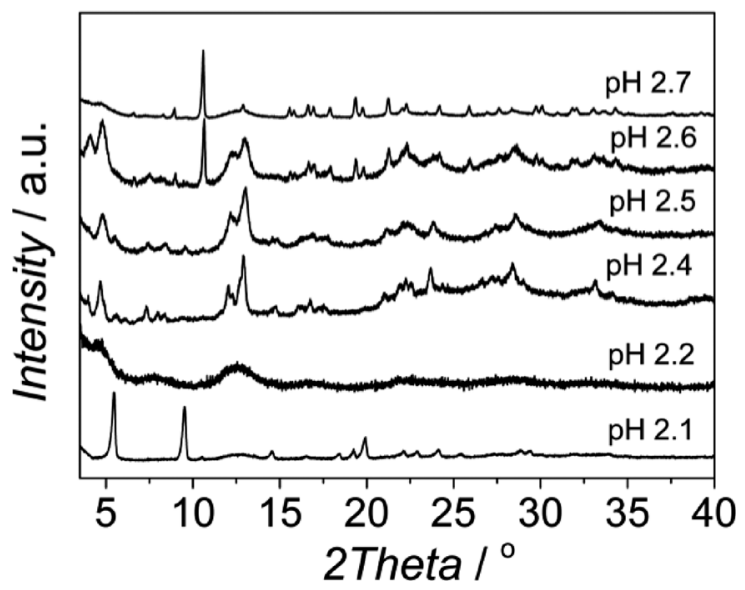

Fig. 2 XRD patterns of the samples obtained at different $\mathrm{pH}$ with $\mathrm{CTAB} / \mathrm{Al}$ and $\mathrm{H}_{2} \mathrm{O} / \mathrm{EtOH}$ molar ratios of 0.6 and 3.4, respectively. 
2.1, 2.4 and 2.7, the calculated BET surface areas were $1365 \mathrm{~m}^{2} \mathrm{~g}^{-1}, 1970 \mathrm{~m}^{2} \mathrm{~g}^{-1}$ and $990 \mathrm{~m}^{2} \mathrm{~g}^{-1}$, respectively (see Fig. 3 and Table 1). The first two values are slightly lower than those previously reported for MIL-110 and MIL-100, ${ }^{32,33}$ suggesting a phase transition upon $\mathrm{pH}$ increase. In the case of MIL-96, different data have been published in the literature. Although some publications claimed that the MIL-96 porosity is not accessible to $\mathrm{N}_{2},{ }^{31}$ other authors have reported BET surface areas as high as $625 \mathrm{~m}^{2} \mathrm{~g}^{-1}$ together with pore volumes of $0.2 \mathrm{~cm}^{3} \mathrm{~g}^{-1}$. ${ }^{4}$ In this work, the micropore pore volume measured was $0.13 \mathrm{~cm}^{3} \mathrm{~g}^{-1}$. However, the coexistence of MIL-96 with phases with higher porosity such as MIL-100 or MIL-110 must be taken into account.

When the acquired SEM images are considered (see Fig. 4), three different morphologies could be observed, in agreement with the results previously published: ${ }^{38}$ elongated hexagonal crystals characteristic of MIL-110 at pH 2.1, small octahedra in the $\mathrm{pH}$ range 2.2-2.5, corresponding to the MIL-100 topology, and a mixture of small octahedra and ill-defined hexagonal crystals due to the coexistence of MIL-100 and MIL-96, respectively, at $\mathrm{pH}$ 2.7. The particle size of MIL-100 depends on the pH (Fig. S4 $\dagger$ ) and decreased from $330 \pm 70 \mathrm{~nm}$ to sizes as small as $30 \pm 5 \mathrm{~nm}$ as the amount of TMAOH in the synthesis solution was increased. Indeed, the addition of a base favours the deprotonation of the

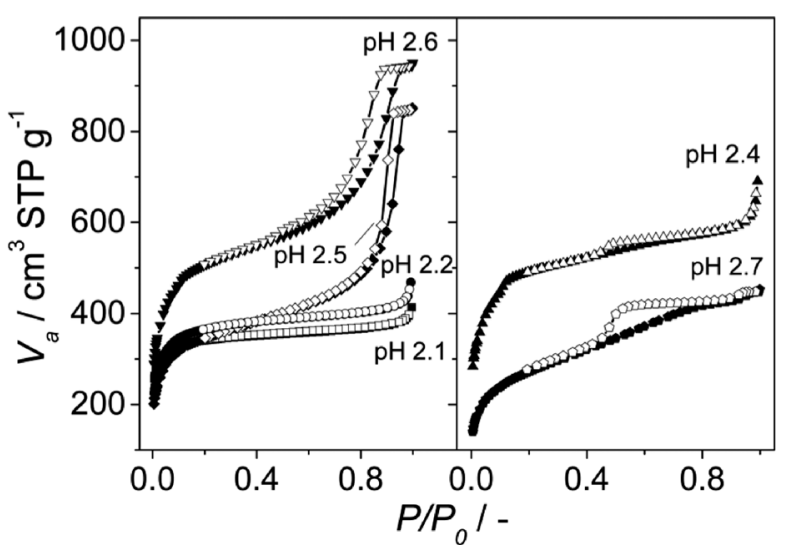

Fig. $3 \mathrm{~N}_{2}$ adsorption isotherms measured at $77 \mathrm{~K}$ on the samples obtained at different $\mathrm{pH}$ with $\mathrm{CTAB} / \mathrm{Al}$ and $\mathrm{H}_{2} \mathrm{O} / \mathrm{EtOH}$ molar ratios of 0.6 and 3.4, respectively. The $\mathrm{pH}$ values used and the topologies obtained were 2.1 (MIL-110), 2.2 (MIL-100), 2.4 (MIL-100), 2.5 (mixture of MIL-100 and MIL-110) and 2.6 and 2.7 (mixture of MIL-100 and MIL-96); see Table 1. Closed symbols represent adsorption and open symbols desorption branch.
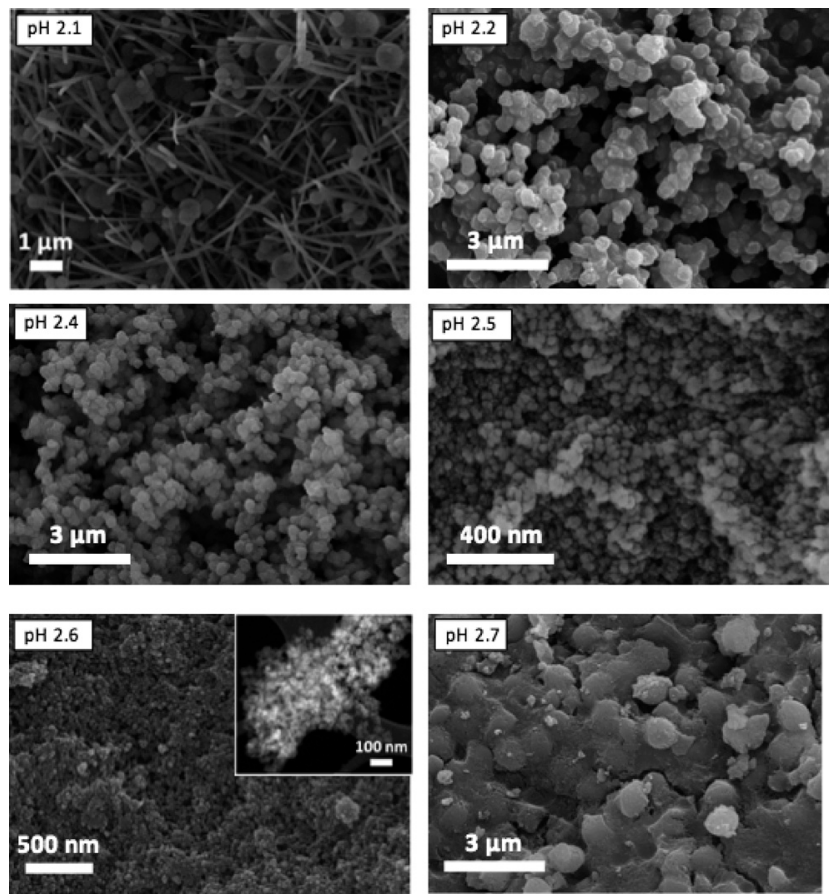

Fig. 4 SEM images of the samples obtained at different $\mathrm{pH}$ from synthesis solutions with $\mathrm{CTAB} / \mathrm{Al}$ and $\mathrm{H}_{2} \mathrm{O} / \mathrm{EtOH}$ molar ratios of 0.6 and 3.4, respectively. The $\mathrm{pH}$ values used and the topologies obtained were 2.1 (MIL-110), 2.2 (MIL-100), 2.4 (MIL-100), 2.5 (mixture of MIL-100 and MIL-110) and 2.6 and 2.7 (mixture of MIL-100 and MIL-96). Inset: TEM image acquired for the MIL-100 sample obtained at $\mathrm{pH} 2.6$.

organic ligand, ${ }^{45}$ increasing its solubility and leading to a more homogenous nucleation, affecting the particle size of the MOF particles and its distribution: the higher the $\mathrm{pH}$ (i.e. better ligand deprotonation), the more homogeneous and smaller the particle size.

Interestingly, although type I isotherms were obtained for the samples synthesized without TМAOH ( $\mathrm{pH} 2.1$ ), clear hysteresis loops were observed at higher $\mathrm{pH}$. The isotherms of the samples synthesized at $\mathrm{pH} 2.4$ and higher exhibit a behavior between types I and IV with large uptake at low pressures and hysteresis (Fig. 3). The large uptake at low pressures is related to the adsorption in the mesoporous cavities of the MIL-100 (25-30 ̊) through its microporous windows (5-8.6 $\AA$ ), while the hysteresis and slope in the adsorption branch may be attributed to condensation in the interparticle mesoporous voids delimited between the MOF nanocrystals (see Fig. 4, inset).

Table 1 Textural properties of the samples obtained at $120{ }^{\circ} \mathrm{C}$ and different $\mathrm{pH}$ with $\mathrm{CTAB} / \mathrm{Al}$ and $\mathrm{H}_{2} \mathrm{O} / \mathrm{EtOH}$ molar ratios of 0.6 and 3.4 , respectively

\begin{tabular}{llllllll}
\hline Run & Phase $[\mathrm{MIL}]$ & $\mathrm{pH}$ & $S_{\text {BET }}\left[\mathrm{m}^{2} \mathrm{~g}^{-\mathrm{m}}\right]$ & $S_{\text {INT }}\left[\mathrm{m}^{2} \mathrm{~g}^{-\mathrm{m}}\right]$ & $S_{\text {EXT }}\left[\mathrm{m}^{2} \mathrm{~g}^{-\mathrm{m}}\right]$ & $S_{\text {EXT }} / S_{\text {INT }}$ & $V_{\text {MICRO }}\left[\mathrm{cm}^{3} \mathrm{~g}^{-1}\right]$ \\
\hline Al_BTC 1 & 110 & 2.1 & 1360 & 1170 & 190 & 0.16 & 0.44 \\
Al_BTC 2 & 100 & 2.2 & 1405 & 1050 & 360 & 0.34 \\
Al_BTC 3 & 100 & 2.4 & 1970 & 1270 & 700 & 0.55 \\
Al_BTC 4 & $100 / 110$ & 2.5 & 1280 & 740 & 720 & 0.72 & 0.49 \\
Al_BTC 5 & $100 / 96$ & 2.6 & 1890 & 1180 & 670 & 0.30 \\
Al_BTC 6 & $96 / 100$ & 2.7 & 990 & & & & 0.47 \\
\end{tabular}


These results are in agreement with the FTIR and TGA analyses (see Fig. S5 and $\mathrm{S}^{\dagger}$ ). At $\mathrm{pH}$ 2.1, the $\mathrm{C}-\mathrm{H}$ stretching band of the СТAB is absent, whereas at $\mathrm{pH} 2.4$ and higher the presence of CTAB in the as-synthesized powder is clearly observed. According to TGA, at pH 2.6 the calculated amount of CTAB in the as-synthesized sample is $6.3 \mathrm{wt} \%$. We hypothesize that at higher $\mathrm{pH}$, ligand deprotonation is accelerated and the carboxylate moieties, besides coordinating the metal ions, may interact with the cationic surfactant. Interestingly, after treatment with EtOH under reflux and under vacuum at $130{ }^{\circ} \mathrm{C}$, the $\mathrm{CTAB}$ was completely removed without affecting the hierarchical porosity of the MOF. The BJH pore size distributions were calculated from the $\mathrm{N}_{2}$ isotherms, the sample synthesized at $\mathrm{pH} 2.5$ exhibiting the narrowest pore size distribution with pore diameters around $32 \mathrm{~nm}$ (Fig. S7†). It is emphasized that the $\mathrm{BJH}$ model was applied to the adsorption branch to avoid the influence of the so-called tensile strength effect (TSE), ${ }^{46}$ indicated by the forced closure of the isotherm at $P / P_{0}=0.42$. When the TSE phenomenon takes place, the $\mathrm{BJH}$ model applied to the desorption branch gives a completely different result compared to that obtained from the adsorption branch, where it is absent, leading to the misinterpretation of the pore size distribution. In the former case, a very well defined mesoporosity with a pore size determined primarily by the nature of the adsorptive is obtained. Surprisingly, in recent studies on mesoporous MOFs a very narrow pore size distribution centered at $3.8 \mathrm{~nm}$, caused by the abovementioned TSE effect, was erroneously attributed to the presence of real, very well defined mesoporosity. ${ }^{42}$

Finally, to assess the effect of the surfactant, synthesis at pH 2.5 was also performed without CTAB. The isotherm acquired for the MOF obtained without a surfactant (Fig. S8†) showed no hysteresis but high uptake at high $P / P_{0}$ (close to $P / P_{0}=1$ ), pointing to the formation of much bigger MOF crystals and condensation in macropores formed around these bigger particles (see Fig. S9†).

\section{Influence of EtOH/ $/ \mathrm{H}_{2} \mathrm{O}$ molar ratio}

The influence of the $\mathrm{H}_{2} \mathrm{O} / \mathrm{EtOH}$ molar ratio at $\mathrm{pH} 2.5$ was also investigated (see Table 2). As shown in Fig. 5, mixtures of MIL-96 and MIL-100 were synthesized in the range $\mathrm{H}_{2} \mathrm{O}$ / EtOH 3.9-9.1. As the ratio was decreased, the relative amount of MIL-100 increased. For mixtures with $\mathrm{H}_{2} \mathrm{O} / \mathrm{EtOH}=1.5$ the powder obtained was already pure MIL-100 and no impurities

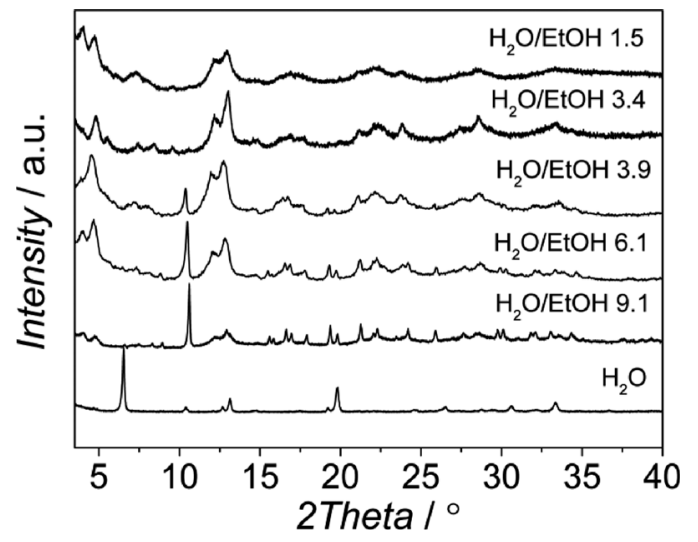

Fig. 5 XRD patterns of the samples obtained at $\mathrm{pH} 2.5$ from synthesis solutions with a CTAB/Al molar ratio of 0.6 and different $\mathrm{H}_{2} \mathrm{O} / \mathrm{EtOH}$ molar ratios.

were observed. This trend suggests that EtOH helps equilibrate the least stable AlBTC (MIL-100), while high concentrations of $\mathrm{H}_{2} \mathrm{O}$ promote the formation of more stable phases (MIL-96) ${ }^{47}$ according to a faster hydrolysis of the kinetic phase at higher water concentrations. ${ }^{48}$

According to the $\mathrm{N}_{2}$ isotherms acquired at $77 \mathrm{~K}$, the lower the amount of ethanol, the broader the pore size distribution in the obtained materials (see Fig. 6 and 7). Samples synthesized at $\mathrm{pH} 2.5$ from mixtures of $\mathrm{H}_{2} \mathrm{O}$ and $\mathrm{EtOH}$ with molar ratios of 1.5 (pure MIL-100), 3.4 (mixture of MIL-100 and MIL-110) and 3.9 (mixture of MIL-100 and MIL-96) exhibited the narrowest $\mathrm{BJH}$ pore size distributions, which are centered at $33 \AA ̊$ (see Fig. 6).

When the synthesis was carried out in distilled water and no ethanol was added, the relative peak intensities of the XRD pattern were significantly different compared to those of the theoretically simulated XRD pattern of the MIL-96 topology. The XRD pattern of the sample obtained in water media (Fig. S10 $\dagger$ ) exhibits a strong increase in the relative intensity of the reflection associated with the $\left(\begin{array}{lll}0 & 0 & 2\end{array}\right)$ plane, which indicates the preferred crystal orientation of the $\left(\begin{array}{lll}0 & 0 & l\end{array}\right)$ planes. To confirm this observation, powder pattern refinements were performed and the preferential orientation was modeled using the March-Dollase function. The powder XRD refinement results (see Table S2 and Fig. S11 $\dagger$ ) confirm a 000 l preferential crystal orientation, the (llll $\left.\begin{array}{lll}0 & 0 & 1\end{array}\right)$ plane running parallel to the bipyramidal cages of the MIL-96 topology (see Fig. S12 $\dagger$ ). Interestingly, the refined $G$-parameters of the

Table 2 Textural properties of the samples synthesized at $120^{\circ} \mathrm{C}$ and $\mathrm{pH} 2.5$ with a $\mathrm{CTAB} / \mathrm{Al}$ molar ratio of 0.6 and different $\mathrm{H}_{2} \mathrm{O} / \mathrm{EtOH}$ molar ratios

\begin{tabular}{lllllll}
\hline Run & Phase $[\mathrm{MIL}]$ & $\mathrm{H}_{2} \mathrm{O} /$ EtOH molar ratio & $S_{\text {BET }}\left[\mathrm{m}^{2} \mathrm{~g}^{-1}\right]$ & $S_{\text {INT }}\left[\mathrm{m}^{2} \mathrm{~g}^{-1}\right]$ & $S_{\text {EXT }}\left[\mathrm{m}^{2} \mathrm{~g}^{-1}\right]$ & $V_{\text {MICRO }}\left[\mathrm{cm}^{3} \mathrm{~g}^{-1}\right]$ \\
\hline Al_BTC 8 & 96 & $\infty$ & 150 & 105 & 50 & 0.04 \\
Al_BTC 9 & $96 / 100$ & 9.1 & 1180 & 620 & 550 & 0.23 \\
Al_BTC 10 & $100 / 96$ & 6.1 & 1280 & 720 & 550 & 0.28 \\
Al_BTC 11 & $100 / 96$ & 3.9 & 1360 & 690 & 670 & 0.26 \\
Al_BTC 4 & $100 / 110$ & 3.4 & 1550 & 670 & 530 & 0.30 \\
Al_BTC 12 & 100 & 1.5 & & & 880 & 0.25
\end{tabular}




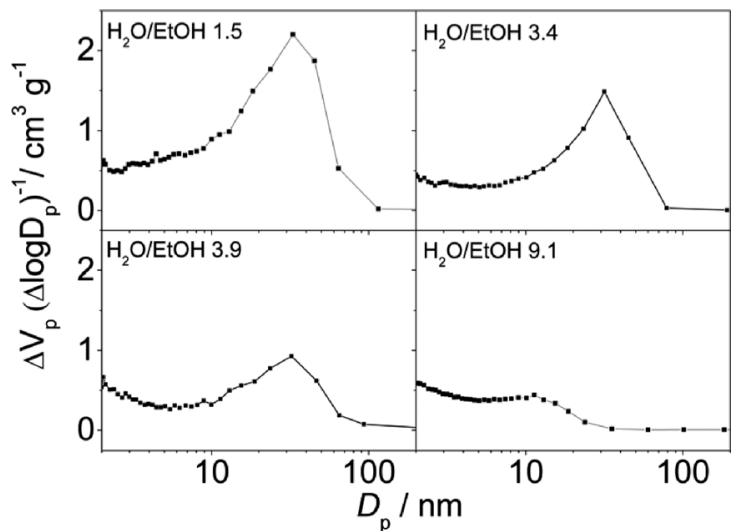

Fig. 6 BJH pore size distribution curves of the samples synthesized at $\mathrm{pH} 2.5$ in mixtures of $\mathrm{H}_{2} \mathrm{O}$ and $\mathrm{EtOH}$ with different molar ratios and a CTAB/Al ratio of 0.6 .

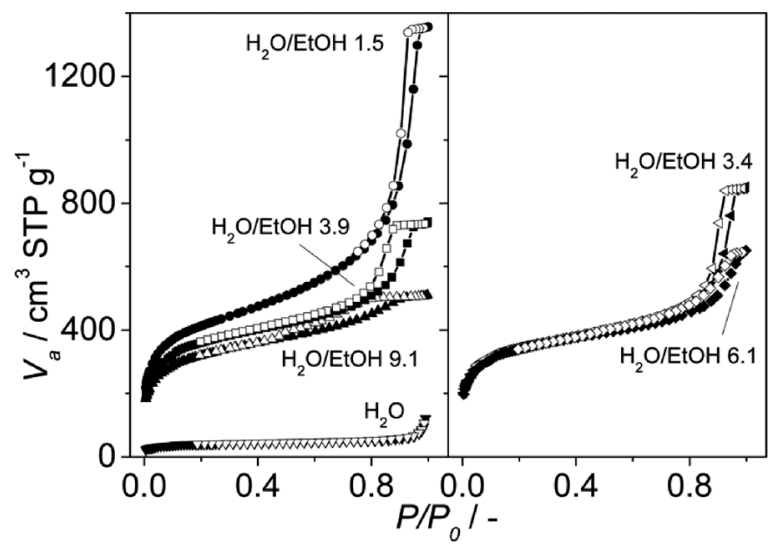

Fig. $7 \mathrm{~N}_{2}$ adsorption isotherms acquired at $77 \mathrm{~K}$ on the samples synthesized at $\mathrm{pH} 2.5$ with different $\mathrm{H}_{2} \mathrm{O}$ /EtOH molar ratios. The $\mathrm{H}_{2} \mathrm{O}$ / EtOH molar ratios used and the topologies obtained were $\infty$ (MIL-96), 9.1, 6.1 and 3.9 (mixture of MIL-100 and MIL-96), 3.4 (mixture of MIL-100 and MIL-110) and 1.5 (MIL-100); see Table 2. Closed symbols represent adsorption and open symbols desorption branch.

March-Dollase function were equal to 0.51, indicating a lamellar particle morphology, in good agreement with the SEM micrographs of this sample and in clear contrast to the ill-defined hexagonal particles formed under "standard" synthesis conditions (see Fig. 8). In the case of MIL-96, the addition of surfactant did not affect the morphology of the MOF particles.

\section{Discussion}

In this work, the synthesis of Al trimesate MOFs in the presence of the well-known cationic surfactant CTAB was studied to investigate the formation of MOFs with hierarchical porosity. Thus, in order to create mesoporosity, the concentration of surfactants used in all the experiments here presented is well above the critical micelle concentration (CMC) for CTAB in water ethanol mixtures. ${ }^{49,50}$ On the one hand, the
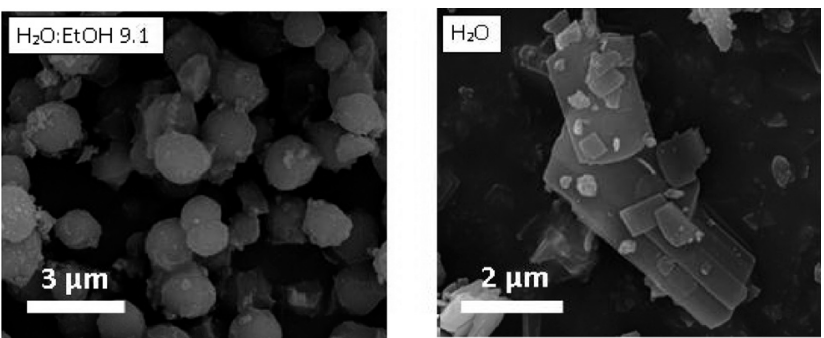

Fig. 8 SEM images of the MIL-96 samples obtained at pH 2.5 in a mixture of $\mathrm{H}_{2} \mathrm{O}$ and EtOH with an $\mathrm{H}_{2} \mathrm{O} / \mathrm{EtOH}$ molar ratio of 9.1 and in distilled water, both with a CTAB/AI molar ratio of 0.6 .

configuration of the surfactant should have a clear effect on the kinetics of formation of the MOF; on the other hand, the concentration of co-solvents (ethanol in our case) and changes in $\mathrm{pH}$ have a strong effect on both MOF precursor solubility and micelle size and configuration.

We speculate that during the synthesis the ligand is incorporated in the hydrophobic interior region of the micelles leading to the expansion and deformation of the micelles formed. It has been shown that during the synthesis of mesoporous aluminas, an increase in the concentration of $\mathrm{EtOH}$ completely suppresses the formation of macropores. ${ }^{50}$ This effect is attributed to the fact that polar, protic cosolvents tend to decrease the aggregation and/or aggregate size of CTAB, leading to highly porous, disordered mesoporous materials. ${ }^{49}$ We therefore speculate that an increase in the concentration of EtOH has a twofold effect: (i) it reduces the size of the CTAB aggregates, leading to a faster exchange between the hydrophilic (Al-containing) phase and the hydrophobic (linker containing) phase as a result of the larger exchange area and (ii) it solubilizes the organic linker better. Because of the small aggregates and fast kinetics, very small MIL-100 particles are formed that lead to the creation of a secondary mesoporosity in the system. The smaller the MIL-100 particles, the better their packing and therefore the narrower the pore size distribution. Indeed, the samples here synthesized with high EtOH concentrations resulted in more homogeneous pore size distributions, while the samples synthesized under low EtOH concentrations present hardly any mesoporosity.

Furthermore, slight changes in $\mathrm{pH}$ will have the same effect: the higher the initial $\mathrm{pH}$, the smaller the aggregates and the faster the ligand deprotonation, leading to the formation of hierarchical MOFs.

Finally, it is also important to stress that, at least in the case of Al based MOFs, it seems quite difficult to synthesize structures with a large degree of meso-order as SBA-15 or MCM-41 and non-ordered interparticle mesoporous voids were observed instead. In fact, several examples of hierarchical MOFs composed of nanoparticles have been published $^{28,51}$ and just in a few cases long-ordered mesopores were achieved. ${ }^{27,30}$ In this sense, the interaction between template, co-solvent(s), metal cations and organic linker in solution deserves special attention and more efforts should be devoted to this interesting topic. 


\section{Conclusions}

Changes in the $\mathrm{pH}$ and in the $\mathrm{H}_{2} \mathrm{O} / \mathrm{EtOH}$ molar ratio in the synthesis of $\mathrm{Al}$ trimesates in the presence of CTAB affect both micelle configuration and linker solubility, giving rise to 3 different topologies: MIL-96, MIL-100 and MIL-110. MIL-110 was obtained without additives to control the $\mathrm{pH}$ and at lower temperatures than those commonly reported. Furthermore, MIL-100 with particle sizes as small as $30 \pm 10 \mathrm{~nm}$ was synthesized. In this latter case, the sample possesses hierarchical mesoporosity, with micropores being related to the MOF topology and mesopores related to interparticle voids. The size of CTAB aggregates in solution determines the degree of mesoporosity of the final sample and the aluminium trimesate phase formed: once the critical micelle formation concentration is reached, small aggregates formed at large CTAB/EtOH ratios resulting in the formation of MIL-100 composites assembled by the agglomeration of small MOF nanoparticles. Finally, platelets of MIL-96 were observed for the first time with a (001) preferential crystal orientation.

Our results demonstrate the importance of interaction at the molecular scale between template, co-solvents(s), metal cations and organic linker in solution. Understanding such interactions is crucial for the design of hierarchical MOFs.

\section{Acknowledgements}

The authors acknowledge financial support from the European Research Council under the European Union's Seventh Framework Programme (FP/2007-2013)/ERC grant agreement no. 335746, CrystEng-MOF-MMM. The authors from the University of Zaragoza thank the Spanish Ministry of Economy and Competitiveness (MINECO) for financial support through the project MAT2013-40556-R.

\section{Notes and references}

1 G. Ferey, Chem. Soc. Rev., 2008, 37, 191-214.

2 H. Furukawa, N. Ko, Y. B. Go, N. Aratani, S. B. Choi, E. Choi, A. O. Yazaydin, R. Q. Snurr, M. O'Keeffe, J. Kim and O. M. Yaghi, Science, 2010, 329, 424-428.

3 G. Ferey and C. Serre, Chem. Soc. Rev., 2009, 38, 1380-1399.

4 M. Eddaoudi, J. Kim, N. Rosi, D. Vodak, J. Wachter, M. O'Keeffe and O. M. Yaghi, Science, 2002, 295, 469-472.

5 O. M. Yaghi, M. O'Keeffe, N. W. Ockwig, H. K. Chae, M. Eddaoudi and J. Kim, Nature, 2003, 423, 705-714.

6 Z. Q. Wang and S. M. Cohen, Chem. Soc. Rev., 2009, 38, 1315-1329.

7 J. Juan-Alcaniz, J. Gascon and F. Kapteijn, J. Mater. Chem., 2012, 22, 10102-10118.

8 P. Horcajada, T. Chalati, C. Serre, B. Gillet, C. Sebrie, T. Baati, J. F. Eubank, D. Heurtaux, P. Clayette, C. Kreuz, J. S. Chang, Y. K. Hwang, V. Marsaud, P. N. Bories, L. Cynober, S. Gil, G. Ferey, P. Couvreur and R. Gref, Nat. Mater., 2010, 9, 172-178.
9 J. Gascon, A. Corma, F. Kapteijn and F. Xamena, ACS Catal., 2014, 4, 361-378.

10 B. Zornoza, C. Tellez, J. Coronas, J. Gascon and F. Kapteijn, Microporous Mesoporous Mater., 2013, 166, 67-68.

11 M. Shah, M. C. McCarthy, S. Sachdeva, A. K. Lee and H.-K. Jeong, Ind. Eng. Chem. Res., 2012, 51, 2179-2199.

12 A. Dhakshinamoorthy, M. Alvaro, Y. K. Hwang, Y.-K. Seo, A. Corma and H. Garcia, Dalton Trans., 2011, 40, 10719-10724.

13 L. F. Song, J. Zhang, L. X. Sun, F. Xu, F. Li, H. Z. Zhang, X. L. Si, C. L. Jiao, Z. B. Li, S. Liu, Y. L. Liu, H. Y. Zhou, D. L. Sun, Y. Du, Z. Cao and Z. Gabelica, Energy Environ. Sci., 2012, 5, 7508-7520.

14 W. M. Xuan, C. F. Zhu, Y. Liu and Y. Cui, Chem. Soc. Rev., 2012, 41, 1677-1695.

15 D. Bradshaw, S. El-Hankari and L. Lupica-Spagnolo, Chem. Soc. Rev., 2014, 43, 5431-5443.

16 X.-S. Wang, S. Ma, D. Sun, S. Parkin and H.-C. Zhou, J. Am. Chem. Soc., 2006, 128, 16474-16475.

17 G. Ferey, C. Serre, C. Mellot-Draznieks, F. Millange, S. Surble, J. Dutour and I. Margiolaki, Angew. Chem., Int. Ed., 2004, 43, 6296-6301.

18 G. Ferey, C. Mellot-Draznieks, C. Serre, F. Millange, J. Dutour, S. Surble and I. Margiolaki, Science, 2005, 309, 2040-2042.

19 A. Sonnauer, F. Hoffmann, M. Froeba, L. Kienle, V. Duppel, M. Thommes, C. Serre, G. Ferey and N. Stock, Angew. Chem., Int. Ed., 2009, 48, 3791-3794.

20 B. Wang, A. P. Cote, H. Furukawa, M. O'Keeffe and O. M. Yaghi, Nature, 2008, 453, 207-211.

21 O. K. Farha, A. O. Yazaydin, I. Eryazici, C. D. Malliakas, B. G. Hauser, M. G. Kanatzidis, S. T. Nguyen, R. Q. Snurr and J. T. Hupp, Nat. Chem., 2010, 2, 944-948.

22 M. G. Goesten, F. Kapteijn and J. Gascon, CrystEngComm, 2013, 15, 9249.

23 H.-L. Jiang, Y. Tatsu, Z.-H. Lu and Q. Xu, J. Am. Chem. Soc., 2010, 132, 5586-5587.

24 Y. Yue, Z.-A. Qiao, P. F. Fulvio, A. J. Binder, C. Tian, J. Chen, K. M. Nelson, X. Zhu and S. Dai, J. Am. Chem. Soc., 2013, 135, 9572-9575.

25 V. Meynen, P. Cool and E. F. Vansant, Microporous Mesoporous Mater., 2009, 125, 170-223.

26 X. Roy and M. J. MacLachlan, Chem. - Eur. J., 2009, 15, 6552-6559.

27 X. Roy, L. K. Thompson, N. Coombs and M. J. MacLachlan, Angew. Chem., Int. Ed., 2008, 47, 511-514.

28 L.-G. Qiu, T. Xu, Z.-Q. Li, W. Wang, Y. Wu, X. Jiang, X.-Y. Tian and L.-D. Zhang, Angew. Chem., Int. Ed., 2008, 47, 9487-9491.

29 Y. J. Zhao, J. L. Zhang, B. X. Han, J. L. Song, J. S. Li and Q. A. Wang, Angew. Chem., Int. Ed., 2011, 50, 636-639.

30 T. Y. Ma, H. Li, Q. F. Deng, L. Liu, T. Z. Ren and Z. Y. Yuan, Chem. Mater., 2012, 24, 2253-2255.

31 T. Loiseau, L. Lecroq, C. Volkringer, J. Marrot, G. Ferey, M. Haouas, F. Taulelle, S. Bourrelly, P. L. Llewellyn and M. Latroche, J. Am. Chem. Soc., 2006, 128, 10223-10230. 
32 C. Volkringer, D. Popov, T. Loiseau, G. Ferey, M. Burghammer, C. Riekel, M. Haouas and F. Taulclle, Chem. Mater., 2009, 21, 5695-5697.

33 C. Volkringer, D. Popov, T. Loiseau, N. Guillou, G. Ferey, M. Haouas, F. Taulelle, C. Mellot-Draznieks, M. Burghammer and C. Riekel, Nat. Mater., 2007, 6, 760-764.

34 K. S. Walton and R. Q. Snurr, J. Am. Chem. Soc., 2007, 129.

35 J. Rouquerol, D. Avnir, C. W. Fairbridge, D. H. Everett, J. H. Haynes, N. Pernicone, J. D. F. Ramsay, K. S. W. Sing and K. K. Unger, Pure Appl. Chem., 1994, 66, 1739-1758.

36 M. F. de Lange, T. J. H. Vlugt, J. Gascon and F. Kapteijn, Microporous Mesoporous Mater., 2014, 200, 199-215.

37 J. Rodriguezcarvajal, Phys. B, 1993, 192, 55-69.

38 M. Haouas, C. Volkringer, T. Loiseau, G. Ferey and F. Taulelle, Chem. Mater., 2012, 24, 2462-2471.

39 M. Haouas, C. Volkringer, T. Loiseau, G. Ferey and F. Taulelle, Chem. - Eur. J., 2009, 15, 3139-3146.

40 M. S. Y. Parast and A. Morsali, Inorg. Chem. Commun., 2011, 14, 645-648.

41 H. Reinsch and N. Stock, Microporous Mesoporous Mater., 2013, 171, 156-165.
42 L. Li, S. Xiang, S. Cao, J. Zhang, G. Ouyang, L. Chen and C.-Y. Su, Nat. Commun., 2013, 4, 1774-1774.

43 M. Gaab, N. Trukhan, S. Maurer, R. Gummaraju and U. Müller, Microporous Mesoporous Mater., 2012, 157, 131-136.

44 M. Maes, L. Alaerts, F. Vermoortele, R. Ameloot, S. Couck, V. Finsy, J. F. M. Denayer and D. E. De Vos, J. Am. Chem. Soc., 2010, 132, 2284-2292.

45 J. Cravillon, R. Nayuk, S. Springer, A. Feldhoff, K. Huber and M. Wiebcke, Chem. Mater., 2011, 23, 2130-2141.

46 J. C. Groen, L. A. A. Peffer and J. Perez-Ramirez, Microporous Mesoporous Mater., 2003, 60, 1-17.

47 N. A. Khan, J. S. Lee, J. Jeon, C. H. Jun and S. H. Jhung, Microporous Mesoporous Mater., 2012, 152, 235-239.

48 E. Stavitski, M. Goesten, J. Juan-Alcaniz, A. Martinez-Joaristi, P. Serra-Crespo, A. V. Petukhov, J. Gascon and F. Kapteijn, Angew. Chem. Int. Ed., 2011, 50, 9624-9628.

49 M. T. Anderson, J. E. Martin, J. G. Odinek and P. P. Newcomer, Chem. Mater., 1998, 10, 311-321.

50 W. Deng, M. W. Toepke and B. H. Shanks, Adv. Funct. Mater., 2003, 13, 61-65.

51 X. X. Huang, L. G. Qiu, W. Zhang, Y. P. Yuan, X. Jiang, A. J. Xie, Y. H. Shen and J. F. Zhu, CrystEngComm, 2012, 14, 1613-1617. 